\title{
Cross-Language Transfer of Phonological Processing Skills and the Development Among Chinese Young Learners of English*
}

\author{
WU Chao, LIU Zhi, WANG Pan \\ Nanchang Business College, Jiangxi, China
}

\begin{abstract}
Increasing research has revealed that phonological sensitivity plays an important part in learning to read alphabetic scripts among L1 English speakers, speakers of other alphabetic languages, and those who use non-Roman alphabetic scripts. The current study shows that, despite the emerging small-unit phonological sensitivity, whether the participants had more sophisticated and large-unit phonological sensitivity? Whether phonological sensitivity is likely to be a general skill reflected in the phonology of all languages and develops regardless of whether an opaque relationship exists between the orthography and the phonology of a language? In addition, the observed inter-connection implies that cross language transfer of phonological processing skills might have occurred from L1 to L2 because of L1 literacy instruction. But the interpretation of the results from this study is not as good as expected. As the phonemic segmentation task was a productive assessment, it posed a greater challenge to the young learners and consequently might have compromised the hypothesis trend of phonological sensitivity. Suggestions for further study would be an employment of tasks with the same type of response. Furthermore, it is positive to recruit preschoolers as well as novice readers so as to demonstrate if Chinese children could only develop sub-syllabic perception in the wake of Hanyu Pinyin instruction.
\end{abstract}

Keywords: phonological sensitivity, cross-language transfer, phonological processing skills

\section{Introduction}

Increasing research has revealed that phonological sensitivity - a competence to analyze oral language into smaller sound units - plays an important part in learning to read alphabetic scripts among L1 English children (Metsala, 1999; Bowey, 2001), children of other alphabetic languages (de Jong, Seveke, \& van Veen, 2000; Winskel \& Widjaja, 2007), and children who use non-Roman alphabetic scripts (Shatil \& Share, 2003; Sieh, 2007).

Although all views agree on the important role of phonological sensitivity, disagreements have existed over whether its evolvement followed a phase-like or a diverse pattern (Gottardo, Stanovich, \& Siegel, 1996; Burgess \& Lonigan, 1998; Muter \& Snowling, 1998). In addition, recent bilingual research has shown a positive cross-language transfer of phonological sensitivity in speakers of various alphabetic languages (Cisero \& Royer, 1995; Comeau, Cormier, Lacroix, \& Grandmaison, 1999). Bialystok, Luk, and Kwan (2005)

\footnotetext{
* Acknowledgement: This research was funded by 2020 "13th Five-Year Plan" Project of Jiangxi Educational Science (Project No:20YB355).

WU Chao, master, associate professor, Department of Foreign Languages, Nanchang Business College, Nanchang, China. LIU Zhi, master, lecturer, Department of Computer, Nanchang Business College, Nanchang, China.

WANG Pan, master, lecturer, Department of Public Elementary Courses, Nanchang Business College, Nanchang, China.
} 
proposed further that such positive transfer occurred only when both languages were written in the same alphabetic system.

In sharp contrast, a great disadvantage is suffered by Chinese learners of English because Chinese has long been considered as a language requiring no perception of phonological consciousness. It seems that, in the L1, no phonological skills are developed frequently by Chinese learners, let alone transfer them to the L2 (de Gelder, Vroomen, \& Bertelson, 1993; Cheung, Chen, Lai, Wong, \& Hills, 2001; Bialystok et al., 2005). The shortage in phonological awareness was ascribed to a complete insufficiency of sound implications in the logographic script (Cheung, 1999).

However, exploration on bi-literacy instruction has shown the possibility that phonological awareness in the L2 is possibly to develop as a result of how L1 is instructed, even when a L2 is processed with distinctively different writing scripts (Gottardo, Yan, Siegel, \& Wade-Woolley, 2001; Wang, Koda, \& Perfetti, 2003). In other words, it is L1 literacy background, rather than writing systems, that might be crucial to develop phonological processing skills.

On the one hand, the current study aimed to explore whether L1 Chinese children, at the beginning of learning the new alphabetic language, could develop phonological processing skills at sub-syllabic level in English. On the other hand, it also make an effort to explore whether these skills could have, due to the method employed to teach Chinese previously, transferred from Chinese to English.

\section{Method}

\section{Participants, Materials, and Procedure}

A total of 40 fourth-graders from two classes were employed from a downtown elementary school in Nanchang, Jiangxi. They were 20 boys and 20 girls. All participants were aged around nine years at the beginning of the experiment ( $M=113.33, S D=3.72$ in months).

The participants had a greater diversity in foreign language learning experience. About $51 \%$ of them began learning English from Grade 3 and received extracurricular English teaching from one to four hours per week. Fewer than a quarter had attended extra English lessons in Grade 1 and Grade 2. The mean of their English instruction length was 29.83 months but a wide difference $(S D=19.23)$ existed among individual learners. None of the participants had any experience of living in an English-speaking country. By contrast, their native language experience was alike. The majority of them spoke Mandarin Chinese, to which they had been exposed to since birth.

Five corresponding tasks in Chinese and English were developed for assessment of phonological sensitivity. They included: (a) rhyme detection, (b) onset detection, (c) rhyme and onset detection, (d) rhyme and onset production, and (e) initial consonant isolation. All English testing items consisted of a CVC syllable structure and Chinese testing items three phonetic symbols.

Chinese assessments were always implemented to the whole class as warm-ups to their English counterparts during class period. In each task, three trials were carried out to demonstrate how to deal with the question items.

Participants were provided correct answers to the trials to help clarifying their reflections. Each Chinese assessment lasted around 25 minutes including trials.

The corresponding English assessment was instantly to the whole class after their completion of a Chinese task. Similarly, three trials were employed to explain what the participants were needed to do in each task. In 
contrast to the Chinese ones, the participants were required to click on the mouse to present their answers in the English detection tasks. All participants were tested individually during breaks in the language lab of the audio visual auditorium of the primary school. Each task took about 10 minutes to complete.

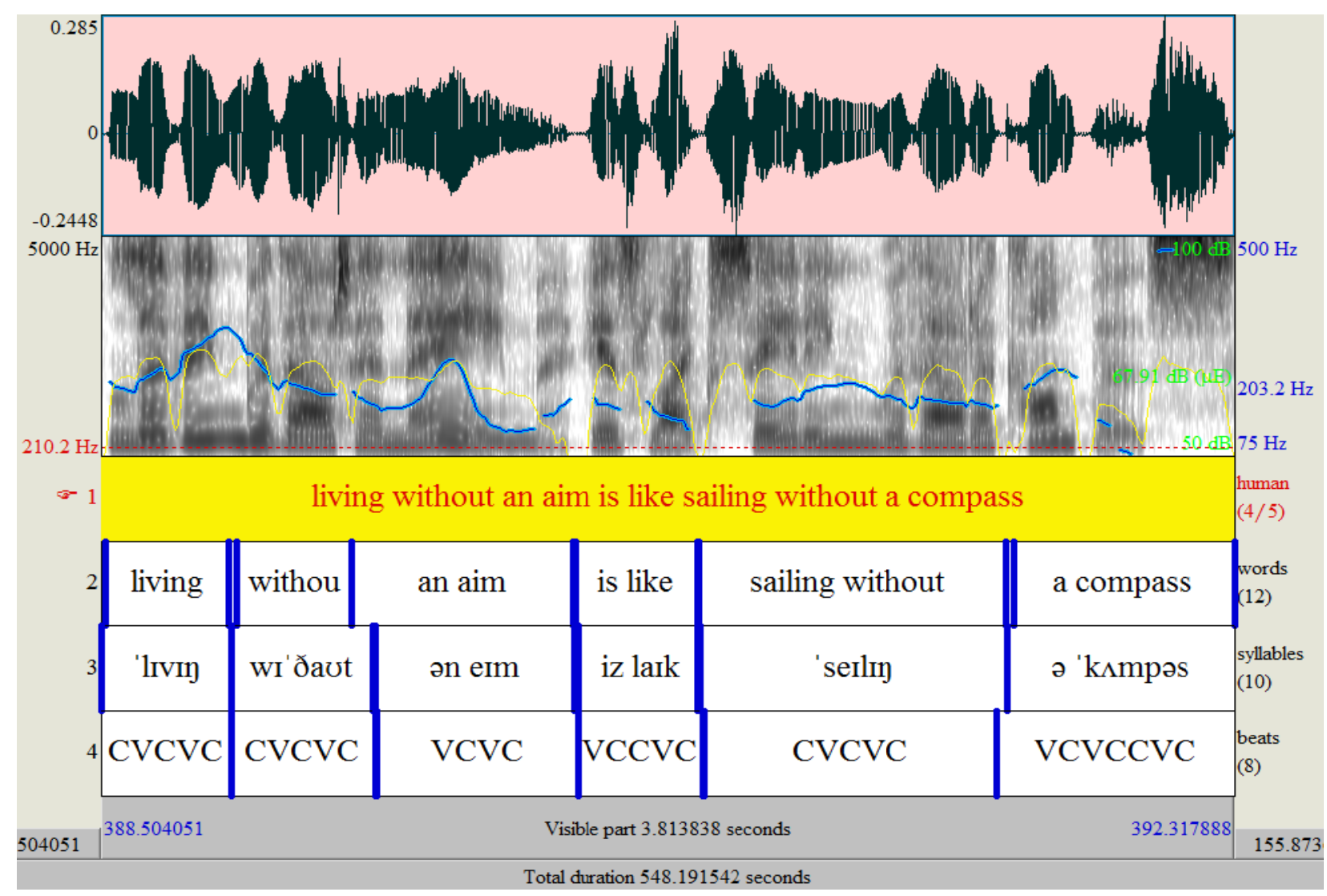

Figure 1. The waveform and spectrogram of the sentence "Living without an aim is like sailing without a compass".

The sentence shown by Figure 1 was uttered by an English native speaker annotated on four tiers: (1) original sentence (top tier); (2) separate words; (3) syllables; and (4) syllabification (bottom tier).

The sentence shown by Figure 2 was uttered by an English native speaker annotated on four tiers: (1) original sentence (top tier); (2) separate words; (3) syllables; and (4) syllabification (bottom tier).

The scores of all tasks were recorded manually except for the three online English detection tasks, whose accuracy was automatically measured by the computer program. One point was awarded for each correct question and the total points awarded for correct answers consisted of the score of a task. 


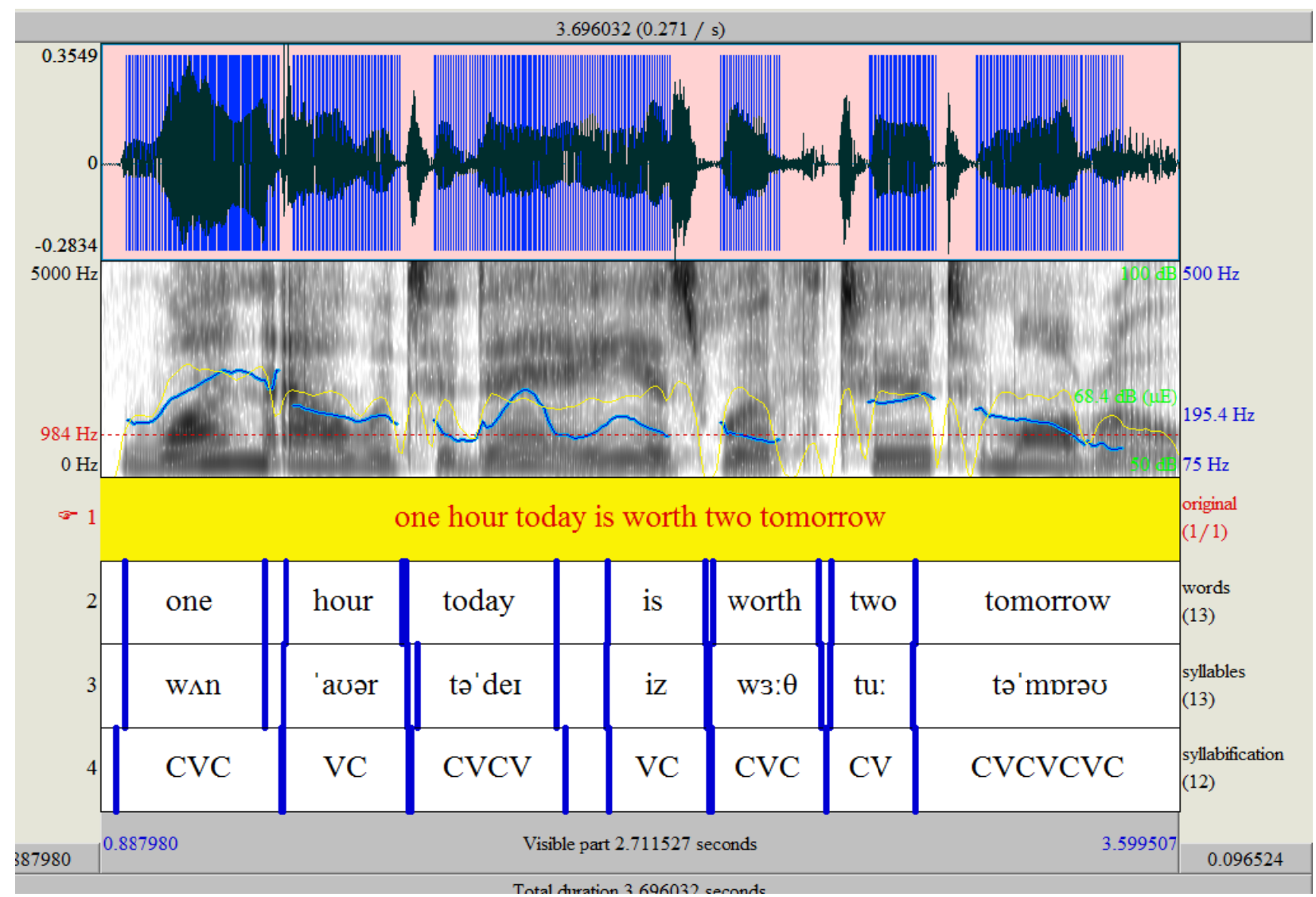

Figure 2. The waveform and spectrogram of the sentence "One hour today is worth two tomorrow".

\section{Results and Discussion}

\section{Development of Phonological Sensitivity From Rhyme to Phoneme}

The participants had a similar experimental pattern of phonological sensitivity in Chinese and English (see Table 1). A paired-samples $t$-test proved that they had more developed phonological sensitivity in their L1 than L2 $(t[40]=-4.576, p<0.000$ [two-tailed]).

Furthermore, the participants obtained more sophisticated large-unit phonological sensitivity when both rhyme detection $(t[40]=12.302$ in L1 and $t[40]=5.174$ in L2, both $p<0.000$ [two-tailed]) and onset detection $(t[40]=7.237$ in L1 and $t[40]=4.609$ in L2, both $p<0.000$ [two-tailed]) were computed against initial consonant isolation. Rhyme sensitivity which is better developed lends support to the claim of a developmental trend from large- to small- unit phonological sensitivity among children (Goswami, 2002). However, although the lower grades in small-unit phonological sensitivity tasks, a diverse developmental pattern seems to be emerging (Muter \& Snowling, 1998).

In addition, the result has an implication in relevant to English as a foreign language (EFL) learners of a non-alphabetic writing system: Phonological sensitivity might be a general perceptional mechanism which would develop regardless of the L1 orthography. In the present research, all participants had been instructed the alphabet and phonics for more than one year when these tasks were carried out to them. Although they had adopted more instruction in small-unit awareness, i.e., phonics, the result shows that they acquired more sophisticated large-unit phonological sensitivity. Large unit phonological sensitivity was likely to be more of a 
universal skill reflected in the phonology of all languages and developed regardless of whether an opaque relationship existed between the orthography and the phonology of a language (Gottardo et al., 2001).

Table 1

Descriptive Statistics for Phonological Processing Assessments $(N=40)$

\begin{tabular}{llllll}
\hline Measure & & M & $\%$ & SD & Max. \\
\hline Chinese tasks & Overall & 13.22 & 66.10 & 2.40 & \\
& Rhyme detection & 16.70 & 83.49 & 2.17 & 20 \\
& Onset detection & 15.25 & 76.27 & 2.83 & 20 \\
& Rhyme \& onset detection & 12.19 & 60.95 & 4.31 & 20 \\
English tasks & Rhyme \& onset production & 10.30 & 51.51 & 4.29 & 20 \\
& Initial consonant isolation & 11.63 & 58.17 & 2.94 & 20 \\
& Overall & 15.04 & 60.16 & 4.19 & \\
& Rhyme detection & 17.97 & 71.87 & 3.89 & 25 \\
& Onset detection & 17.17 & 68.70 & 3.60 & 25 \\
& Rhyme \& onset detection & 16.59 & 66.35 & 4.99 & 25 \\
& Rhyme \& onset production & 10.27 & 41.08 & 6.67 & 25 \\
\hline
\end{tabular}

\section{Cross-Language Transfer of Phonological Sensitivity}

Plenty of relevant analyses revealed moderate inter-connection between corresponding tasks in Chinese and English shown in the diagonal line (see Table 2), indicating that cross-language transfer of phonological processing skills might have occurred.

The fact that the participants had better developed Chinese phonological sensitivity implies that such sensitivity was more likely to transfer from their L1 to L2, rather than vice versa. The finding is the same with that of previous study on alphabetic language users (Cisero \& Royer, 1995; Comeau et al., 1999) and on learners with a non-alphabetic language background (Bialystok et al., 2005; Gottardo et al., 2001; Wang et al., 2003).

\section{Table 2}

Inter-correlations Between Phonological Sensitivity Tasks in Two Languages Skills

\begin{tabular}{lllllll}
\hline $\begin{array}{l}\text { Chinese Task } \\
\text { English Task }\end{array}$ & 1 & 2 & 3 & 4 & 5 & 6 \\
\hline Overall & 0.679 & 0.477 & 0.552 & 0.659 & 0.568 & 0.440 \\
Rhyme detection & 0.543 & 0.403 & 0.344 & 0.500 & 0.480 & 0.383 \\
Onset detection & 441 & 0.355 & 0.380 & 0.352 & 0.282 & 0.382 \\
Rhyme \& onset detection & 571 & 0.355 & 542 & 0.539 & 0.473 & 0.382 \\
Rhyme \& onset production & 613 & 0.423 & 0.4590. & 606 & 0.515 & 0.411 \\
Initial consonant isolation & 0.211 & 0.198 & 0.166 & $0.304^{*}$ & 0.246 & -0.015 \\
\hline
\end{tabular}

Note. ${ }^{*} p<0.05$.

The strategies of teaching Chinese children might account for this unexpected finding. Taiwanese children learn to read Chinese with the assistance of Hanyu Pinyin, a separate phonetic script. They first learn to read each of the 37 phonetic symbols and then group or regroup two or three of them together to sound out a Chinese character. As Hanyu Pinyin is placed alongside each Chinese character in the texts of all textbooks from Grade 1 to Grade 4, and alongside only fresh words from Grade 5, Chinese children are employed to combining phonetic symbols to pronounce new words. 
In other words, Hanyu Pinyin has unintentional taught Chinese children to practise phonological units at phonemic level, which might have, in turn, enabled the participants in the current study to apply their L1 phonological sensitivity when dealing those English tasks.

\section{Conclusion}

The results from the current study show that, despite the emerging small unit phonological sensitivity, the participants had more sophisticated large unit phonological sensitivity, which is likely to be a general skill reflected in the phonology of all languages and develops regardless of whether an opaque relationship exists between the orthography and the phonology of a language. In addition, the observed inter-connection implies that cross language transfer of phonological processing skills might have occurred from L1 to L2 because of L1 literacy instruction.

But the interpretation of the results is not as good as expected. As the phonemic segmentation task was a productive assessment, it posed a greater challenge to the young learners and consequently might have compromised the hypothesis trend of phonological sensitivity. Suggestions for further study would be an employment of tasks with the same type of response. Furthermore, it is positive to recruit preschoolers as well as novice readers so as to demonstrate if Chinese children could only develop sub-syllabic perception in the wake of Hanyu Pinyin instruction.

\section{References}

Bialystok, E., Luk, G., \& Kwan, E. (2005). Bilingualism, biliteracy, and learning to read: Interactions among languages and writing systems. Scientific Studies of Reading, 9(1), 43-61.

Bowey, J. A. (2001). Non-word repetition and young children's receptive vocabulary: A longitudinal study. Applied Psycholinguistics, 22(3), 441-469.

Burgess, S. R., \& Lonigan, C. J. (1998). Bidirectional relations of phonological sensitivity and prereading abilities: Evidence from a preschool sample. Journal of Experimental Child Psychology, 70(2), 117-141.

Cheung, H. (1999). Improving phonological awareness and word reading in a later learned alphabetic script. Cognition, 70(1), $1-26$.

Cheung, H., Chen, H. C., Lai, C. Y., Wong, O. C., \& Hills, M. (2001). The development of phonological awareness: Effects of spoken language experience and orthography. Cognition, 81(3), 227-241.

Cisero, C. A., \& Royer, J. M. (1995). The development and cross-language transfer of phonological awareness. Contemporary Educational Psychology, 20(3), 275-303.

Comeau, L., Cormier, P., Grandmaison, E., \& Lacroix, D. (1999). A longitudinal study of phonological processing skills in children learning to read in a second language. Journal of Educational Psychology, 91, 29-43.

de Gelder, B., Vroomen, J., \& Bertelson, P. (1993). The effects of alphabetic reading competence on language representation in bilingual Chinese subjects. Psychological Research, 55(4), 315-321.

de Jong, P. F., Seveke, M., \& van Veen, M. (2000). Phonological sensitivity and the acquisition of new words in children. Journal of Experimental Child Psychology, 76(4), 275-301.

Goswami, U. (2002). In the beginning was the rhyme? A reflection on Hulme, Hatcher, Nation, Brown, Adams and Stuart (2002). Journal of Experimental Child Psychology, 82(1), 47-57.

Gottardo, A., Stanovich, K. E., \& Siegel, L. S. (1996). The relationships between phonological sensitivity, syntactic processing, and verbal working memory in the reading performance of third-grade children. Journal of Experimental Child Psychology, 63(3), 563-582.

Gottardo, A., Yan, B., Siegel, L. S., \& Wade-Woolley, L. (2001). Factors related to English reading performance in children with Chinese as a first language: More evidence of cross-language transfer of phonological processing. Journal of Educational Psychology, 93(3), 530-542.

Metsala, J. L. (1999). Young children's phonological awareness and non-word repetition as a function of vocabulary development. Journal of Educational Psychology, 91(1), 3-19. 
Muter, V., \& Snowling, M. (1998). Concurrent and longitudinal predictors of reading: The role of metalinguistic and short-term memory skills. Reading Research Quarterly, 33(3), 320-337.

Shatil, E., \& Share, D. L. (2003). Cognitive antecedents of early reading ability: A test of the modularity hypothesis. Journal of Experimental Child Psychology, 86(1), 1-31.

Sieh, Y. C. (2007). Phonological processing skills in young learners' EFL vocabulary acquisition (Unpublished Ph.D. thesis, Newcastle University, England, 2007).

Wang, M., Koda, K., \& Perfetti, C. A. (2003). Alphabetic and non-alphabetic L1 effects in English word identification: A comparison of Korean and Chinese English L2 learners. Cognition, 87(2), 129-149.

Winskel, H., \& Widjaja, V. (2007). Phonological awareness, letter knowledge, and literacy development in Indonesian beginner readers and spellers. Applied Psycholinguistics, 28(1), 23-45. 